\title{
Correlation of serum vitamin $D$ level with the disease severity in vernal keratoconjunctivitis patients
}

\author{
Tanushree $V^{1, *}$, Vinuta Mohan Kulkarni² \\ ${ }^{\mathbf{1}}$ Assisstant Professor, ${ }^{2}$ Junior Resident, Dept. of Ophthalmology, Bangalore Medical College and Research Institute, Bangalore, \\ Karnataka, India
}

*Corresponding Author: Tanushree V

Email: tanushree19686@gmail.com

\begin{abstract}
Purpose: Study aims to correlate serum vitamin D level to disease severity in children with vernal keratoconjunctivitis.

Materials and Methods: 50 patients in the age group between 5-15 years attending the out patient department of Ophthalmology from December 2017 to March 2018 were enrolled in the study. After detailed evaluation, vernal keratoconjunctivitis diagnosed based on signs and symptoms. Severity of the disease documented. Patients were started on treatment for vernal keratoconjunctivitis. Serum vitamin D level was obtained for all the patients. Patients with low level vitamin D were noted and treated for the same. Data collected and analysed using descriptive statistics.

Results: Out of 50 patients, 36 were males and 14 were females. Mean age of presentation was 13 years. Serum vitamin D was less than $20 \mathrm{ng} / \mathrm{mL}$ in $38(76 \%)$ patients. In patients with mild to moderate disease it was between $10-20 \mathrm{ng} / \mathrm{mL}$ and was significantly lower $(<10 \mathrm{ng} / \mathrm{mL})$ in severe vernal keratoconjunctivitis patients and showed significant correlation with severity of the disease.

Conclusion: Children with vernal keratoconjunctivitis have low vitamin D level as a consequence of sun exposure avoidance due to intense photophobia and pruiritis. Evaluation of vitamin D level in vernal keratoconjunctivitis patients can help in early diagnosis and treatment.
\end{abstract}

Keywords: Disease severity, Serum vitamin D, Vernal keratoconjunctivitis.

\section{Introduction}

Vernal

keratoconjunctivitis

(Vernal keratoconjunctivitis) is a chronic allergic disease. It is the inflammation of the ocular surface, involving tarsal or bulbar conjunctiva. ${ }^{1,2}$ It is usually bilateral, at times asymmetrical, seasonally exacerbated condition. Vernal keratoconjunctivitis is relatively more common in warm and dry climate countries. It occurs on seasonal basis, more common during late spring and summer. Vernal keratoconjunctivitis is one of the most common cause of outpatient morbidity among pediatric population in our region.

Clinically characterised by presence of papillae, limbal thickening along with limbal papillae, superior punctate epithelial erosions. Condition causes significant morbidity due to intense pruiritis, photophobia, redness and characteristic sticky, ropy discharge. Pruritus may be exacerbated by exposure to wind, dust, bright light, hot weather that affects the quality of life mainly by making them avoid sun exposure. ${ }^{3}$ Inadequate exposure to sunlight being the major cause of vitamin D deficiency is known to be exaggerated in patients of vernal keratoconjunctivitis due to significant morbidity. As vernal keratoconjunctivitis mainly affects younger population, it is important to detect early the complications, so that appropriate treatment can be given. So this study was conducted to look for the correlation of serum vitamin D level with disease severity in patients with vernal keratoconjunctivitis in our population so as to detect vitamin D deficiency early and give appropriate treatment.

\section{Materials and Methods}

A prospective study was conducted on patients attending outpatient department of the Minto Regional Institute of Ophthalmology, Bangalore medical college and research institute, Bangalore from December 2017 to May 2018. Total of 50 vernal keratoconjunctivitis patients were identified and included in the study. The history of each patient was taken including a record of age, sex, place of residence, change of place of residence, age at onset of the disease. Best-corrected visual acuity was assessed and each patient was thoroughly examined with a slit lamp. The diagnosis of vernal keratoconjunctivitis was made on history, detailed slit lamp examination. Severity of the disease was graded into mild, moderate, severe based on the clinical features including symptoms, presence of various characteristic signs as described by Bonini et al and treatment started. ${ }^{4}$ Serum vitamin D level was evaluated for all the patients enrolled in the study and the data collected. Correlation of vitamin D level with the disease severity noted. Patients with low vitamin D level treated with vitamin D supplementation as per paediatrician advice. Data collected and analysed using descriptive statistics.

\section{Results}

Out of 50 patients included in the study 36 were males and 14 were females showing male preponderance (Table 1). Age distribution was found to be from 5-20years with mean age of presentation of 13 (Table 2). Male to female was found to be 2.5:1. 
Commonly reported symptom was itching $(84 \%)$, redness $(72 \%)$ and discolouration of eye $(56 \%)$ (Table 3 ). Common signs included palpebral papillae $(85 \%)$, limbal thickening (75\%) with other signs being superficial punctate epithelial erosions, plaque, shield ulcer, keratoconus in varying percentage (Table 4). Based on the above features, about 16 patients had mild disease, 18 patients had moderate disease and 6 patients had severe disease (Fig. 1).

Serum vitamin D level in patients with mild to moderate disease was found to be $10-20 \mathrm{ng} / \mathrm{mL}$ and in patients with severe disease it was less than $10 \mathrm{ng} / \mathrm{mL}$ (Fig. 2) Serum vitamin D level showed significant correlation with the disease severity. (Table 5)

Table 1: Sex distribution

\begin{tabular}{|l|c|c|}
\hline \multicolumn{1}{|c|}{ Sex } & No & Percentage \\
\hline Males & 36 & 72 \\
\hline females & 14 & 28 \\
\hline
\end{tabular}

Table 2: Age distribution

\begin{tabular}{|l|c|c|}
\hline \multicolumn{1}{|c|}{ Age (yrs) } & No & Percentage \\
\hline $5-10$ & 12 & 24 \\
\hline $11-15$ & 36 & 72 \\
\hline $16-20$ & 2 & 4 \\
\hline
\end{tabular}

Table 3: Presentation

\begin{tabular}{|l|c|c|}
\hline \multicolumn{1}{|c|}{ Symptom } & No & Percentage \\
\hline Itching & 42 & 84 \\
\hline Redness & 36 & 72 \\
\hline Discolouration of eye & 28 & 56 \\
\hline
\end{tabular}

Table 4: Signs

\begin{tabular}{|l|c|c|}
\hline \multicolumn{1}{|c|}{ Sign } & No & Percentage \\
\hline Palpebral papillae & 42 & 85 \\
\hline Limbal thickening & 37 & 75 \\
\hline SPE & 42 & 85 \\
\hline Shield ulcer & 2 & 4 \\
\hline Keratoconus & 5 & 10 \\
\hline
\end{tabular}

Table 5: Correlation of vitamin D level with severity grading

\begin{tabular}{|c|c|c|c|c|}
\hline \multirow[t]{2}{*}{ Grade } & \multirow[t]{2}{*}{$\begin{array}{l}\text { Total } \\
\text { Cases }\end{array}$} & \multicolumn{2}{|c|}{$\begin{array}{c}\text { Serum vitamin D } \\
\text { level }\end{array}$} & $P$ value \\
\hline & & $10-20 \mathrm{ng}$ & $<10$ ng & \multirow{5}{*}{$<0.001$} \\
\hline Mild & 16 & 12 & 0 & \\
\hline Moderate & 18 & 16 & 0 & \\
\hline Severe & 6 & 2 & 4 & \\
\hline Total & 50 & 30 & 4 & \\
\hline
\end{tabular}

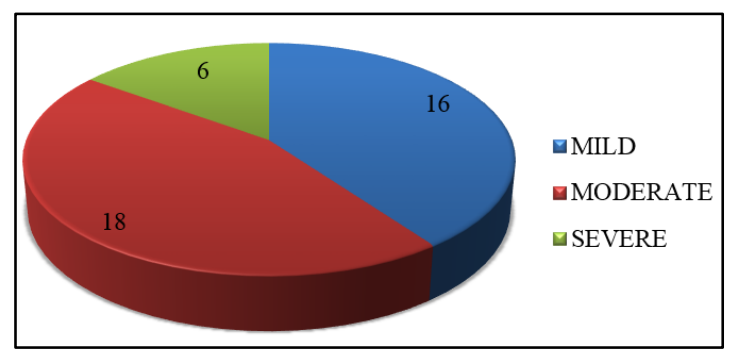

Fig. 1: Clinical grading

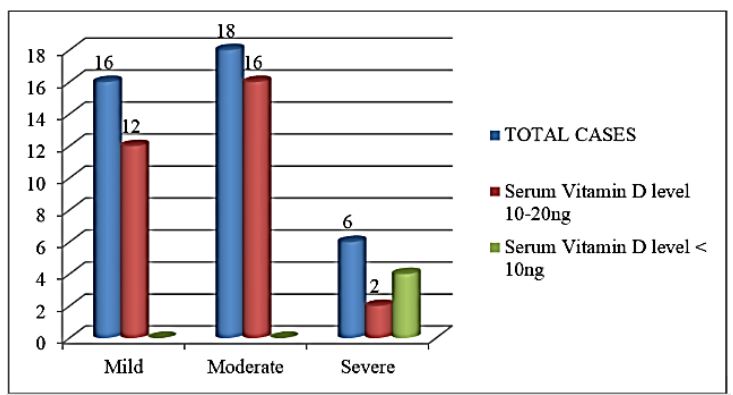

Fig. 2: Correlation of vitamin D level with severity grading

\section{Discussion}

Vernal keratoconjunctivitis is an recurrent inflammatory disease of allergic etiology affecting mainly the young male in hot and dry climate. Patients suffering from vernal keratoconjunctivitis may have several episodes of active inflammation throughout the year significantly affecting the quality of life. Due to chronicity and recurrence, younger population affected may be reluctant to go to schools, play. Although this is not usually a blinding disease, it will affect the quality of life of the patients.

Our study showed male preponderance with male to female ratio of 2.5:1. Most of the studies have shown male preponderance that is attributed to hormonal factors. In one of the large study done by Leonardi et al, also showed male preponderance. Also another study done by Lambaise et al on Italian population also showed that males are more affected than females. ${ }^{5,6}$ Similar results are shown in studies conducted on Nigeria and Saudi arabia. ${ }^{7,8}$ However, few studies have shown that females are more affected like in as study by Ukponmwan et al. ${ }^{9}$

Vernal keratoconjunctivitis is known to be the disease of childhood, mean age of our patients was 13years, but we had 2 cases who presented at age of 18 years. In one of the South Indian study done by Saboo US et al also showed that most of the cases are under 20 years. ${ }^{10}$ A hospital-based study done in Pakistan by Shafiq and Shaikh found only $6 \%$ of patients above

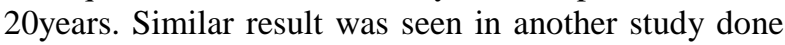
by Leonardi et al showing very less affected cases to be above the age of 20 years. ${ }^{11,5}$ Most of the studies show that younger population is affected and hence timely 
detection, treatment becomes very important to prevent complication.

The main pathophysiology in cases of vernal keratoconjunctivitis is the presence of $\operatorname{Ig} \mathrm{E}$ antibodies defined as Atopy or Type 1 hypersensitivity reaction. There is also role of Th 2 cells involvement. So most of the cases of vernal keratoconjunctivitis will be associated with other atopic diseases such as asthma, rhinitis, urticarial. This will cause significant morbidity to the patients. Important cells involved in the process are mast cells, eosinophils, $\mathrm{T}$ cells and macrophages. Various mediators involved in the pathophysiology includes cytokines, histamines and several growth factors released.

Quality of life is significantly affected mainly due to symptoms of intense pruiritis and photophobia. In a study done by Sacchetti $\mathrm{M}$ et al, it was shown that there was significant changes in behaviour due to symptoms such as preference to be indoors avoiding sun exposure. ${ }^{3}$ Most parents of the affected children are worried about the symptoms that will restrict children activities. This can also make the child inattentive in schools and late to schools. Due to photophobia, most children will prefer to be indoors and avoiding sun exposure can lead to vitamin D deficiency. Vitamin D deficiency is defined as serum vitamin $\mathrm{D}$ level less than 20ng/mL. Vitamin D deficiency affects almost $50 \%$ of the population world wide which can mainly be attributed to lifestyle and environmental factors that reduce exposure to sunlight, which is required for ultraviolet-B induced vitamin $D$ production in the skin. ${ }^{12}$ Vitamin D deficiency results in abnormalities in calcium, phosphorus, and bone metabolism causing a generalized decrease in bone mineral density (BMD), resulting in osteopenia and osteoporosis. Serum vitamin $\mathrm{D}$ level is found to decreased in all the patients of vernal keratoconjunctivitis in our study. Severity of disease correlated with the serum level with 6 cases having severely low vitamin d level less than $10 \mathrm{ng} / \mathrm{mL}$. Similar result was found in the study done by Zicari AM et al. ${ }^{13}$ Another study done by Bozkurt B et al also showed that serum vitamin D levels is low in vernal keratoconjunctivitis patients. ${ }^{14}$ Not many studies have been done on this aspect.

Treatment of vernal keratoconjunctivitis involves various aspects. General measure such as cool compression, avoiding allergan and maintaining lid hygiene is important. Bandage contact lens can be used in severe cases. Specific treatments includes mast cell stabilisers such as sodium cromoglicate, topical anti histaminics such as epinastine, bepotastine. Combined anti histaminics and vasoconstrictor also shown to be effective. Non steroidal inflammatory preparations may improve comfort, topical steroids in short but intensive doses will be more effective. In resistant cases, immune modulators such as cyclosporin, tacrolimus can be used. Oral antihistamines, immunosuppressive agents can be used in refractory cases. Along with all these patients with decreased vitamin $\mathrm{D}$ level due to sun exposure avoidance needs to supplemented with vitamin D supplementation. Early detection of vitamin D deficiency in such patients can help to treat the condition effectively. Timely vitamin D supplementation can be given to prevent further complication in vernal keratoconjunctivitis patients along with the treatment for vernal keratoconjunctivitis disease. Vitamin D level in human beings is effected by various dietary and environmental factors acting as confounding factor in our study which is a limitation of our study.

\section{Conclusion}

Vernal keratoconjunctivitis is mainly seen in young children that significantly affects the quality of life causing avoidance of sun exposure due to intense photophobia and pruiritis. Vitamin D which is a unique vitamin that requires sun exposure for its production may thus be reduced in vernal keratoconjunctivitis patients. Vitamin D is required for many important functions in the body. Thus early detection of vitamin D deficiency vernal keratoconjunctivitis patients is thus necessary for appropriate and timely treatment.

\section{References}

1. Leonardi A, Secchi AG. Vernal keratoconjunctivitis. Int Ophthalmol Clin. 2003;43:41-58.

2. Bonini S, Coassin M, Aronni S, Lambiase A. Vernal keratoconjunctivitis. Eye (Lond). 2004;18:345-51.

3. Sacchetti M, Baiardini I, Lambiase A, Aronni S, Fassio $\mathrm{O}$, Gramiccioni $\mathrm{C}$, et al. Development and testing of the quality of life in children with vernal keratoconjunctivitis questionnaire. Am J Ophthalmol. 2007;144:557-63.

4. Bonini S, Sacchetti M, Mantelli F, Lambiase A. Clinical grading of vernal keratoconjunctivitis. Curr Opin Allergy Clin Immunol. 2007;7:436-41.

5. Leonardi A, Busca F, Motterle L, Cavarzeran F, Fregona IA, Plebani M, et al. Case series of 406 vernal keratoconjunctivitis patients: A demographic and epidemiological study. Acta Ophthalmol Scand. 2006;84:406-10.

6. Lambiase A, Minchiotti S, Leonardi A, Secchi AG, Rolando M, Calabria G, et al. Prospective, multicenter demographic and epidemiological study on vernal keratoconjunctivitis: A glimpse of ocular surface in Italian population. Ophthalmic Epidemiol. 2009;16:3841.

7. Tabarra KF. Ocular complications of vernal keratoconjunctivitis. Can J Ophthalmol. 1999;34:88-92.

8. Akinsola FB, Sonuga AT, Aribaba OT, Onakoya AO, Adefule-Ositelu AO. Vernal keratoconjunctivitis at Guinness Eye Centre, Luth (a five year study). Nig $Q J$ Hosp Med. 2008;18:1-4.

9. Ukponmwan CU. Vernal conjunctivitis in Nigerians: 109 consecutive cases. Trop Doct. 2003;33:242-5.

10. Saboo US, Jain M, Reddy JC, Sangwan VS. Demographic and clinical profile of vernal keratoconjunctivitis at a tertiary eye care center in India. Indian J Ophthalmol. 2013;61:486-9. 
11. Shafiq I, Shaikh ZA. Clinical presentation of vernal keratoconjunctivitis (Vernal keratoconjunctivitis): A hospital based study. J Liaquat Univ Med Health Sci. 2009;8:50-4.

12. Nair R, Maseeh A. Vitamin D: The "sunshine" vitamin. Journal of Pharmacology \& Pharmacotherapeutics. 2012;3(2):118-126.

13. Zicari AM, Cafarotti A, Occasi F, Lollobrigida V, Nebbioso $\mathrm{M}$ et al. Vitamin D levels in children affected by vernal keratoconjunctivitis. Curr Med Res Opin. 2017 Feb;33(2):269-27.

14. Bozkurt B, Artac H, Ozdemir H, Ünlü A, Bozkurt MK, Irkec M. Serum Vitamin D Levels in Children with Vernal Keratoconjunctivitis. Ocul Immunol Inflamm. 2018;26(3):435-439.

How to cite this article: Tanushree V, Kulkarni V. M. Correlation of serum vitamin D level with the disease severity in vernal keratoconjunctivitis patients. Indian J Clin Exp Ophthalmol. 2018;4(4):439-442. 